\title{
Indirect effects of bleaching on predator deterrence in the tropical Pacific soft coral Sinularia maxima
}

\author{
Marc Slattery $^{1, *}$, Valerie J. Paul ${ }^{2}$ \\ ${ }^{1}$ Department of Pharmacognosy and the National Center for Natural Products Research, School of Pharmacy, \\ The University of Mississippi, University, Mississippi 38677-1848, USA \\ ${ }^{2}$ Smithsonian Marine Station at Fort Pierce, 701 Seaway Drive, Fort Pierce, Florida 34949, USA
}

\begin{abstract}
The environmental stress theory (EST) suggests that stress-induced biochemical changes will make an organism more susceptible to predation relative to unstressed individuals. Bleaching represents a stress response in marine invertebrate host-zooxanthellae symbiont associations, including those species that rely on chemical defenses to reduce predation pressure. We examined the EST in the context of a natural soft coral bleaching event, and then by use of a 3 mo transplant/shading field experiment that also resulted in bleaching. Feeding experiments using an omnivorous pufferfish indicated that extracts of bleached soft corals were more palatable to predators than were those from unbleached individuals. Two biochemical constituents were significantly reduced in naturally- and experimentally-bleached soft corals: lipid and defensive metabolite (pukalide) concentration. While a sunscreen (palythine) was significantly lower immediately after a natural bleaching event, it recovered and even exceeded pre-bleached levels in experimentallybleached soft corals. Feeding assays with pukalide and lipid at concentrations representative of unbleached and bleached soft corals indicate that pufferfish are not deterred by bleached levels of the defensive metabolite, but that pufferfish are less attracted to food with bleached levels of lipid. Nonetheless, field observations of up to 4 times higher predation on bleached soft corals suggest that defensive metabolite concentration may have a greater influence on predation than food quality. This study indicates that a stress response (bleaching) has an indirect effect on predator deterrence in the soft coral Sinularia maxima due to changes in biochemical constituents that affect food quality.
\end{abstract}

KEY WORDS: Environmental stress theory - Chemical defenses - Bleaching · Sunscreens Transplants

Resale or republication not permitted without written consent of the publisher

\section{INTRODUCTION}

The production of defensive metabolites is often assumed to divert energy from basic metabolic requirements including growth, reproduction, maintenance, and resource acquisition. A variety of models have been proposed to account for patterns of resource allocation to defenses and these other fundamental processes (Cronin 2001). The environmental stress theory (EST) was proposed to explain increased palatability of physiologically-stressed terrestrial plants; it suggests that decreases in defensive compounds or increases in nutritional value of the plants could account for observed increases in herbivory (White 1984, Rhoades 1985). Changes in these plant biochemical constituents might occur if a stressed individual exhibits either (1) reduced efficiency in acquiring requisite resources, or (2) increased maintenance costs associated with physiological repair relative to an unstressed individual. While the role of abiotic factors in structuring marine communities has been well documented, the impacts of abiotic stressors on marine algal and invertebrate defenses have rarely been studied (Renaud et al. 1990, Cronin \& Hay 1996a, 
Michalek-Wagner \& Bowden 2000). However, the importance of interactions between prey nutritional quality and chemical defenses in predation has received more attention in marine communities (Duffy \& Paul 1992, Hay et al. 1994, Cruz-Rivera \& Hay 2003); although this is untested, some of the prey caloric value is likely due to lipid (Stimson 1987).

Coral-bleaching is one of the most apparent environmental stress responses in the marine environment (Glynn 1993). This phenomenon, which can occur in any invertebrate-zooxanthellae association, has been reported with alarming and increasing frequency worldwide (Brown 1997). The loss of zooxanthellae symbionts by the invertebrate host tissue (i.e. 'bleaching') may prevent host cellular damage through oxidative stress induced by elevated sea temperatures (Lesser 1997), or radiation (UV-B, UV-A, and PAR: $\lambda=$ 280-319 nm, 320-399 nm, 400-700 nm, respectively, Baruch et al. 2005), or a combination of these factors (Douglas 2003). Loss of zooxanthellae can have a significant impact on the metabolic health and budget of the host organism since these symbionts are important in nitrogen and phosphorous cycling within the association, and they contribute up to $95 \%$ of their photosynthetic products to the host (Muller-Parker \& D'Elia 1997). As photosynthesis declines with the reduction in chl a levels during bleaching (Warner et al. 2002), many corals are forced to utilize stored carbon reserves in protein, carbohydrates, and lipid (Anthony et al. 2002, Grottoli et al. 2004). Protein and carbohydrates typically represent a short-term solution to a bleached coral's metabolic requirements (Anthony et al. 2002), while the significant energetic resources in lipid (Stimson 1987) can support coral metabolism for almost 3 mo (Montipora verrucosa, Spencer Davies 1991). Coral energetic budget deficits imply some degree of tradeoff in resource allocation to metabolic activities and other functions including defense (Cronin 2001).

Many soft corals maintain symbioses with zooxanthellae, and during bleaching events these organisms are often severely stressed (Michalek-Wagner \& Willis 2001). We observed bleaching in about half the population of the soft coral Sinularia maxima on a shallow reef off Guam during November 1994. This event appeared to be much more influenced by solar radiation than temperature (i.e. bleaching occurred at a depth $\leq 1 \mathrm{~m}$ following a $2 \mathrm{wk}$ period of sunny days with exceptionally clear and still water, even though water temperature never exceeded $28^{\circ} \mathrm{C}_{i}$ this study). Bleached soft corals exhibited an increase in the number of predation events (as measured by bite scars, Slattery et al. 2001) compared to unbleached conspecifics. This was surprising since $S$. maxima contains various cembranoid diterpene feeding deterrent compounds (Wylie \& Paul 1989, Slattery et al. 1998), although these can vary in time and space (Slattery et al. 2001). S. maxima also sequesters a mycosporinelike amino acid (MAA; this study) which has the potential to absorb in the UV spectral range thus acting as a natural sunscreen (see references in Shick 2004, for review). The purpose of this study was to (1) describe the biochemical differences (i.e. quantitative and qualitative variation in primary and secondary metabolites between bleached and unbleached soft corals, (2) characterize the effects of solar radiation on the soft coral-zooxanthellae association, and (3) determine whether bleached soft coral colonies are more palatable to predators than are unbleached conspecifics.

\section{MATERIALS AND METHODS}

Study site. The soft coral Sinularia maxima is a ubiquitous member of shallow-water reefs of the IndoPacific, and it is one of the most abundant soft corals on the leeward reefs of Guam $\left(13^{\circ} 25^{\prime} \mathrm{N}_{i} 144^{\circ} 55^{\prime} \mathrm{E}\right)$ (Slattery et al. 2001). At Cocos Lagoon, the southwestern-most reef of Guam, S. maxima co-occurs with $S$. paulae and $S$. polydactyla on back reef flats at depths of $\leq 2 \mathrm{~m}$ (although these latter 2 species exhibited no signs of bleaching during this study). In addition, a population of $S$. maxima is located on the northern slope of Marc's Reef, adjacent to the boat channel at a depth of $15 \mathrm{~m}$.

Naturally-bleached soft coral collections. On 13 November 1994 we collected replicate ( $\mathrm{n}=15$ each) colonies of bleached and unbleached Sinularia maxima samples from a depth of $1 \mathrm{~m}$, and unbleached colonies from a depth of $15 \mathrm{~m}$. Unbleached $S$. maxima specimens have a characteristic pinkish-tan pigmentation; the bleached colonies exhibited a total lack of pigment across the colony surface. Bite marks were recorded on bleached and unbleached soft coral colonies using procedures described in Slattery et al. (2001). An additional 45 bleached and 45 unbleached colonies from $1 \mathrm{~m}$, and 45 unbleached colonies from $15 \mathrm{~m}$ were tagged for subsequent sampling in each of following 3 mo ( $\mathrm{n}=15$ per treatment each mo) in order to assess recovery from bleaching. These soft corals were returned to the University of Guam Marine Laboratory (UOGML) for subsequent processing of zooxanthellae and biochemical constituents, and for feeding assays (see below). Once each month of the study (on collection days: 11 December 1994, 8 January 1995, and 5 February 1995; see below), the light quality and quantity were recorded at this site hourly between 09:00 and 16:00 h using an IL1400A radiometer/photometer equipped with UVA/B and PAR detectors (International Light). UVA and PAR measurements were collected with UV-stabilized silicon photodiode 
detectors that included flat-response filtration in the PAR (400-750 nm) and UVA (315-390 nm) wavelengths at noise equivalent irradiances of $5.00 \mathrm{e}^{-10} \mathrm{~W} \mathrm{~cm} \mathrm{~cm}^{-2}$ and $2.67 \mathrm{e}^{-10} \mathrm{~W} \mathrm{\textrm {cm } ^ { - 2 }}$, respectively. UVB measurements were collected with a solar blind vacuum photodiode detector that included filtration in the UVB (185-320 nm; $\left.\lambda_{\max }=240 \mathrm{~nm}\right)$ wavelength at a noise equivalent irradiance of $6.67 \mathrm{e}^{-6} \mathrm{~W} \mathrm{~cm} \mathrm{~cm}^{-2}$. These survey days were generally sunny with very limited cloud cover and no rain. While these days represented the best conditions noted throughout the course of the study, winter tends to be the dry season on Guam, so irradiance is typically not affected by atmospheric conditions. Thus our data are considered representative of the light environment supporting these soft corals.

Quantification of zooxanthellae and soft coral chemical constituents. The soft coral samples were subdivided into 4 pieces for the following analyses. Zooxanthella densities were determined by homogenizing soft coral tissue samples of $1 \mathrm{~g}$ wet wt in sterile seawater (SSW) and counting the number of symbiont cells using a hemacytometer; care was taken to assure that tissues were collected from the same region of each soft coral colony, representing similar surface areas (ca. $1 \mathrm{~cm}^{2}$ ). Triplicate subsamples from each soft coral were counted and the mean used as a representative of the total density of soft coral zooxanthellae in host tissue. The protein and lipid concentrations of the soft coral-zooxanthellae association were determined from a second tissue subsample of approximately $2 \mathrm{~g}$ wet wt (mass is the typical unit of measurement for alcyonacean soft corals due to extensive variability in their hydrostatic skeletons, and consequently volume [Slattery \& McClintock 1995]; this study duplicated the aforementioned procedures). This subsample was lyophilized, ground and extracted in $1 \mathrm{~N} \mathrm{NaOH}$ for protein analyses (using a colorimetric assay), or 2:1 chloroform/methanol for lipid analyses (using a gravimetric technique). A third subsample of approximately $5 \mathrm{~g}$ wet wt of soft coral tissue was extracted in a 1:1 mixture of dichloromethane/methanol to provide a crude extract containing the soft coral defensive metabolites. These extracts were subsequently used in feeding assays (see below) and for quantification of the defensive metabolites pukalide and 11 $\beta$-acetoxypukalide using analytical HPLC techniques described in Slattery et al. $(1998,2001)$. A fourth subsample of $0.3 \mathrm{~g}$ dry wt of soft coral tissue was extracted in a $4: 1$ mixture of methanol and water to recover MAAs. The polar extract was examined spectrophotometrically; MAAs were separated and quantified in comparison with known standards using analytical HPLC, as described in Karentz et al. (1991).

Artifical bleaching experiment. To determine the effect of solar radiation on soft coral symbiont and biochemical constituents, we conducted a combination transplant/shading study. We reasoned that the differences in susceptibility to bleaching within the shallow-water Sinularia maxima population were due to differing clades of light-acclimatized zooxanthellae (in accordance with Rowan et al. 1997 and MichalekWagner et al. 2001). We postulated further that the population of $S$. maxima from $15 \mathrm{~m}$ would exhibit low tolerance to the solar radiation conditions of the shallow reef, resulting in bleaching. Thus, we transplanted replicate soft corals from the $15 \mathrm{~m}$ site to the $1 \mathrm{~m}$ site, and into each of 4 treatment conditions on 11 December 1994. One treatment was exposed to full sunlight and the remaining 3 treatments were under different Plexiglas ${ }^{\circledR}$ shades. The 3 shaded conditions included (1) UV-transparent Plexiglas ${ }^{\circledR}$ II filter (UVT: allows passage of all UV and visible light $>275 \mathrm{~nm}$ ) (2) UV-opaque Plexiglas ${ }^{\circledR}$ UF3 filter (UVO: allows passage of all visible light $>450 \mathrm{~nm}$ ), and (3) Plexiglas ${ }^{\circledR}$ II filter painted black (PARO/UVO: blocks passage of all UV and visible light). The Plexiglas ${ }^{\circledR}$ shades were $30.5 \times 30.5 \times 0.3 \mathrm{~cm}$; these were cable tied to 4 pieces of $0.9 \mathrm{~cm}$ diameter reinforcing iron bar hammered into the reef flat $(\mathrm{n}=10$ shades per treatment condition). Three soft corals (approximate size: $5 \mathrm{~cm}^{3}$ ) were positioned directly under the middle of each replicate shade, and since these shades were typically no more than $15 \mathrm{~cm}$ above the substratum, minimal direct incident sunlight reached the soft coral colonies throughout the day. This experiment was conducted for $3 \mathrm{mo}$, and at $4 \mathrm{wk}$ intervals (i.e. 8 January 1995, 5 February 1995, and 4 March 1995) one of the 3 transplants under each of the shade treatments, as well as one from the full sunlight condition, were harvested and transported to UOGML for processing as above ( $\mathrm{n}=10$ [replicates] treatment ${ }^{-1} \mathrm{mo}^{-1}$ ). These shades were cleaned of fouling organisms at least once per week through the course of the experiment. In addition to these shade treatments, we transplanted soft corals from the shallow reef to the deep reef, and we back-transplanted soft corals from both sites into their site of origin as a procedural control for handling effects (Slattery et al. 2001). These shallow to deep transplants $\left(\mathrm{n}=5 \mathrm{mo}^{-1}\right)$, and back-transplants ( $\mathrm{n}=5 \mathrm{mo}^{-1}$ from each depth) were collected during each of our 3 subsequent sampling dates. In this transplant study, replicates refer to unique individuals collected from the larger Sinularia maxima population throughout Cocos Lagoon. However given their clonality (Slattery et al. 2001) it is possible that some of the soft corals used in this project might represent ramets of a specific genotype. The effect on our analyses should be to reduce variation, thus the data presented here represent a conservative estimate of stressrelated responses in Sinularia maxima. 
Feeding deterrence assays. Feeding assays were conducted in the laboratory at UOGML using the crude extracts and pure metabolites from the bleached and unbleached colonies of Sinularia maxima collected immediately following a natural bleaching event and immediately following an experimentally-induced bleaching event. The omnivorous pufferfish Canthigaster solandri was used as a model predator (e.g. Slattery et al. 1998) since it feeds occasionally on soft coral polyps in the field. This laboratory assay design was described thoroughly by Slattery et al. (1998). Briefly, pufferfish were maintained in flow-through containers and offered pre-weighed paired $1 \mathrm{~cm}^{3}$ food cubes consisting of a control and a treatment diet. The control food cubes were formulated with $2.5 \mathrm{~g}$ agar in $50 \mathrm{ml}$ of tap water, mixed with $12 \mathrm{~g}$ wet wt of Prime Reef ${ }^{\circledR}$ Aquarium food that contained protein levels similar to those of the soft coral $(\approx 14 \%)$ but lipid levels about half natural levels $(\approx 30 \%)$. To increase lipid levels within the food cubes, we extracted unbleached hard corals (Porites rus, apparently lacking chemical defenses: M. Slattery pers. obs.) collected at the study site using the extraction schemes of Slattery \& McClintock (1995), and added the gravimetric equivalent lipid to our artificial diet. Lipid level was adjusted lower by reducing the concentration of Prime Reef in our food cubes by about one half, and then amending the diet with squid paste. Since squid mantle has much higher levels of protein and lower levels of lipid than the aquarium formulation, mathematical adjustment allowed us to effectively maintain protein concentrations while decreasing lipid concentrations in our control diet. Treatment cubes were formulated in a similar manner but included an ecologically-relevant concentration of the extract or metabolites (see below: 'Results'). A second set of control and treatment cubes was produced identically, but maintained in flow-through containers without pufferfish to control for changes in the food cube mass due to hydration (see Cronin \& Hay 1996a, Slattery et al. 1998). Feeding preference or deterrence was assessed by calculating differences in the adjusted mass of the food cubes consumed.

The interactive effects of defensive metabolite (pukalide) and lipid variability on feeding preference or deterrence were assessed in a similar set of bioassays. Four different combinations of these 2 biochemical constituents were formulated as combination diets in the aforementioned food cubes, representing the extremes of these constituents recorded throughout the study: (1) high concentration of pukalide (= $0.5 \%$ : feeding deterrent levels reported by Slattery et al. 2001) and high concentration of lipid (= $30 \%$ : see Fig. 2B); (2) low concentration of pukalide $(=0.125 \%$ : see Fig. 2D) and high concentration of lipid; (3) high concentration of pukalide and low concentration of

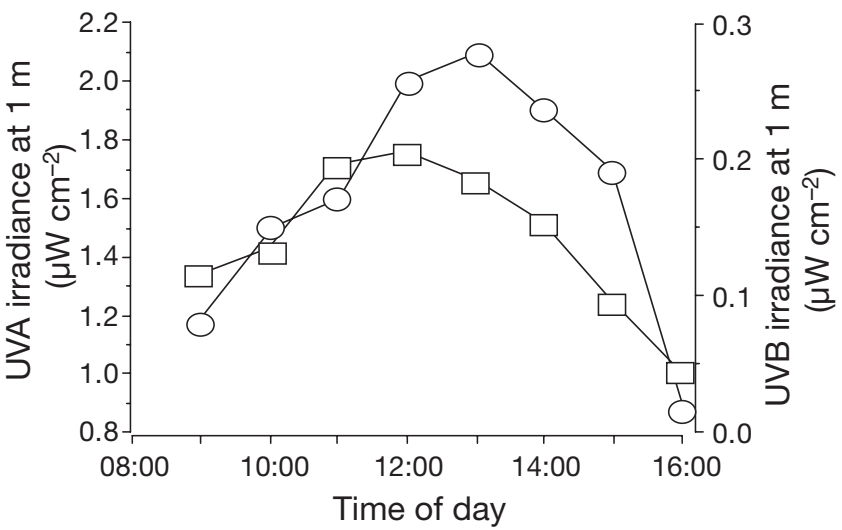

Fig. 1. Representative UV quality and quantity measurements at Cocos Lagoon, Guam. Presented are the means of 4 monthly measurements from November 1994 to February 1995; error bars have been removed for visual clarity. UVA (O) and UVB ( $\square$ ) measurements were collected hourly using an International IL1400A radiometer/photometer at a depth of $1 \mathrm{~m}$. These data were compared to readings collected at the surface, under UV transparent screens, under UV opaque screens, under PAR-UV opaque screens, and at $15 \mathrm{~m}$ depth (see 'Results')

lipid (= $10 \%$ : see Fig. 2B); and (4) low concentration of pukalide and low concentration of lipid. Since we were interested in potential additivity or synergisms with respect to feeding preference or deterrence, we also conducted single constituent pair-wise assays (i.e. control diet amended with pukalide, or control diet amended with lipid, only). These $4 \times 3$ blocked pairwise comparisons (i.e. 2 single constituent and one combination constituent assays) were all conducted for identical periods of time $(1.75 \mathrm{~h})$ so that results of the individual assays could be compared across the block in a higher-order statistical manner (Hay et al. 1994).

Statistical analyses. The changes in soft coral symbiont densities and biochemical constituent concentrations following a natural bleaching event and an experimentally-induced (transplant/shading) bleaching event were analyzed using factorial ANOVA with date and soft coral condition as fixed factors. The data, presented as percentages, were arcsin transformed prior to analyses, and tested for assumptions of normality and equal variance. Post hoc tests for multiple comparisons included Sheffe's $S$ and Dunnett's tests. Field bite mark data on bleached and unbleached soft corals were compared with a 2 -sample $t$-test. Feeding assays using naturally- and experimentally-bleached soft coral extracts were tested using a paired $t$-test between control and treatment cubes based on mass differences adjusted for hydration. The blocked single constituent/combination constituent assays were analyzed first by paired $t$-tests, and then (using the difference between control and treatment consumption for 
each assay) the data were analyzed by ANOVA with diet condition as a fixed factor (see Hay et al. 1994 for description of technique). Data are presented as mean $\pm \mathrm{SD}$.

\section{RESULTS}

The surface irradiance in Guam during the late fall to early winter (i.e. November 1994 to February 1995) averaged $26.34 \pm 17.84 \mu \mathrm{W} \mathrm{cm}{ }^{-2}$ PAR, $1.85 \pm 1.27 \mu \mathrm{W}$

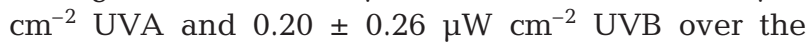
course of an average day (Fig. 1). Surface irradiance was measured at 11:00 in the morning each month and was typically in the range of $27.8 \mu \mathrm{W} \mathrm{cm} \mathrm{cm}^{-2} \mathrm{PAR}, 1.6 \mu \mathrm{W}$ $\mathrm{cm}^{-2}$ UVA and $0.2 \mu \mathrm{W} \mathrm{cm}^{-2}$ UVB. Solar irradiance attenuation at $1 \mathrm{~m}$ and $15 \mathrm{~m}$ averaged about $11 \%$ and $26 \%$, respectively. UV transparent shades (UVT) caused an insignificant drop in ambient UV $(\approx 1.5 \%$ :

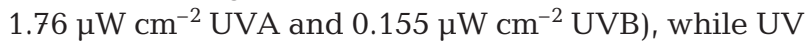
opaque (UVO) and blackened shades (PARO/UVO) reduced ultraviolet irradiance to levels consistent with dusk $\left(0.3 \mu \mathrm{W} \mathrm{cm}{ }^{-2}\right.$ UVA and $\left.0.01 \mu \mathrm{W} \mathrm{cm}{ }^{-2} \mathrm{UVB}\right)$.

\section{Naturally-bleached soft coral}

Sinularia maxima colonies consistently contained 3 defensive metabolites: 2 feeding deterrent compounds (pukalide and 11 $\beta$-acetoxypukalide) and one natural sunscreen (the MAA palythine, $\lambda_{\max }=320 \mathrm{~nm}$ ); these were used as biomarkers of bleaching effects. Following a natural bleaching event, the soft corals exhibited significant variability in zooxanthella densities and lipid, pukalide and palythine concentrations through time (Fig. 2A,B,D,F). Each of these parameters was
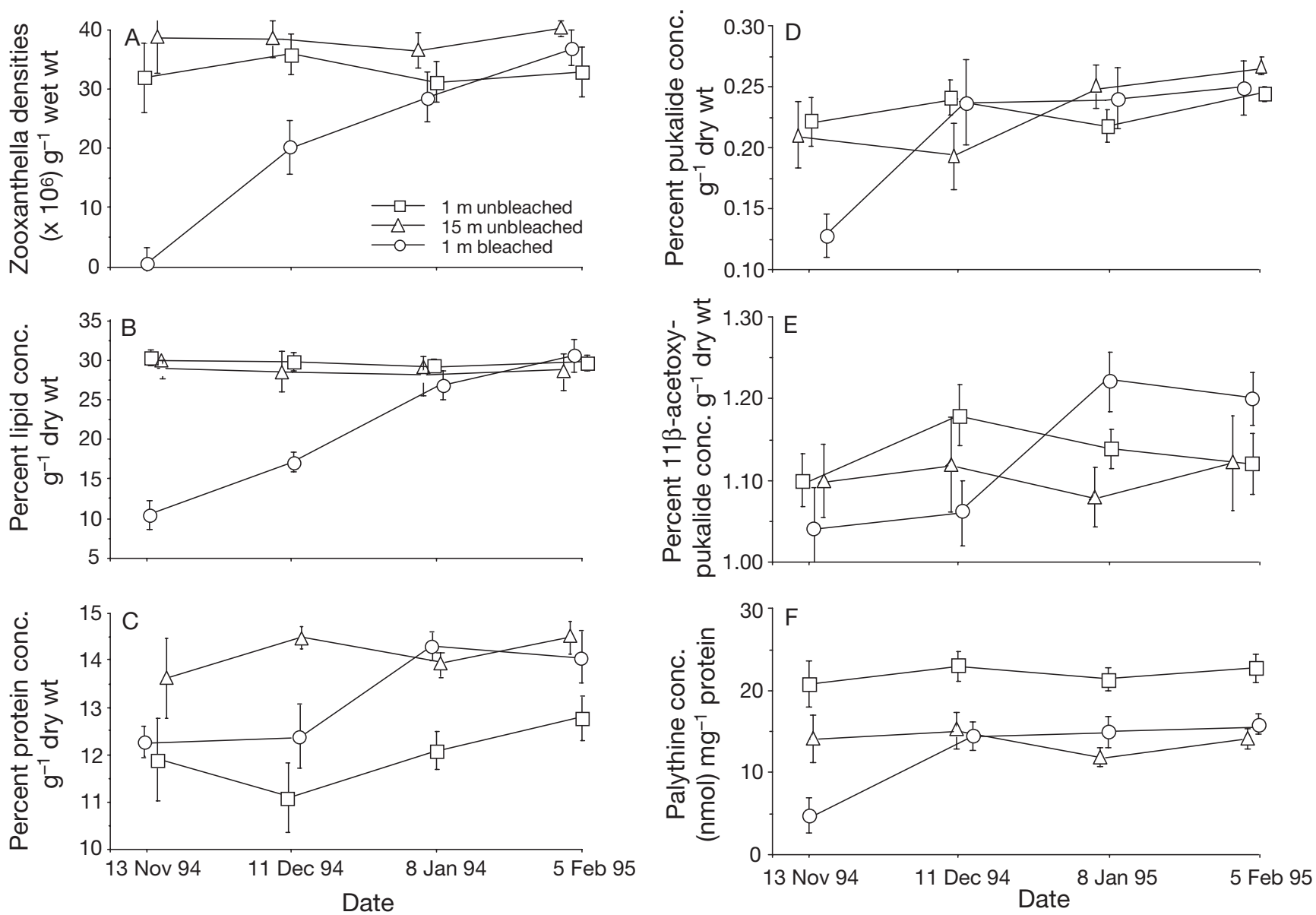

Fig. 2. Changes in zooxanthella densities and biochemical concentrations in the soft coral Sinularia maxima following a natural bleaching event in Guam. Compared are bleached soft corals from $1 \mathrm{~m}$ depth $(0)$, unbleached soft corals from $1 \mathrm{~m}$ depth $(\square)$, and unbleached soft corals from $15 \mathrm{~m}$ depth $(\Delta)$ each month from November $1994\left(\mathrm{~T}_{0}\right)$ to February $1995\left(\mathrm{~T}_{3}\right)$. Data points represent the mean $( \pm \mathrm{SD} ; \mathrm{n}=15$ replicates per treatment) for (A) zooxanthella densities, (B) \% lipid concentration, (C) \% protein concentration, (D) \%pukalide concentration, (E) \%11 acetoxypukalide concentration, and (F) palythine concentration. Note difference in scales (y-axis) for each parameter 
significantly lower in bleached than in unbleached corals collected from the same shallow-water population in November 1994 (ANOVA $_{\text {zooxanthellae: }}$ MS $=6.464$, $F_{3,168}=4.518, \mathrm{p}=0.0151 ;$ ANOVA $_{\text {lipid }}: \mathrm{MS}=371.493$, $F_{3,168}=9.031, \mathrm{p}=0.0004 ;$ ANOVA $_{\text {pukalide }}: \mathrm{MS}=0.008$, $F_{3,168}=4.086, \mathrm{p}=0.0220 ;$ ANOVA $_{\text {palythine: }} \mathrm{MS}=$ $\left.2316.078, F_{3,168}=3.447, \mathrm{p}=0.0386\right)$. The recovery of these soft coral parameters to pre-bleaching levels occurred within a 1 to 2 mo period (Scheffe's $S$ : p < 0.05 at $\mathrm{T}_{0}\left[13\right.$ Nov 94] and $\mathrm{T}_{1}$ [11 Dec 94] for zooxanthella densities and lipid concentration, and $p<0.05$ at $\mathrm{T}_{0}$ only for pukalide and palythine concentration). Palythine and protein concentrations were the only parameters that exhibited significant differences between the shallow- and deep-water populations, with increased concentrations directly correlated to solar irradiance (Scheffe's $S: \mathrm{p}<0.05$ at $\mathrm{T}_{0}$ to $\mathrm{T}_{3}$
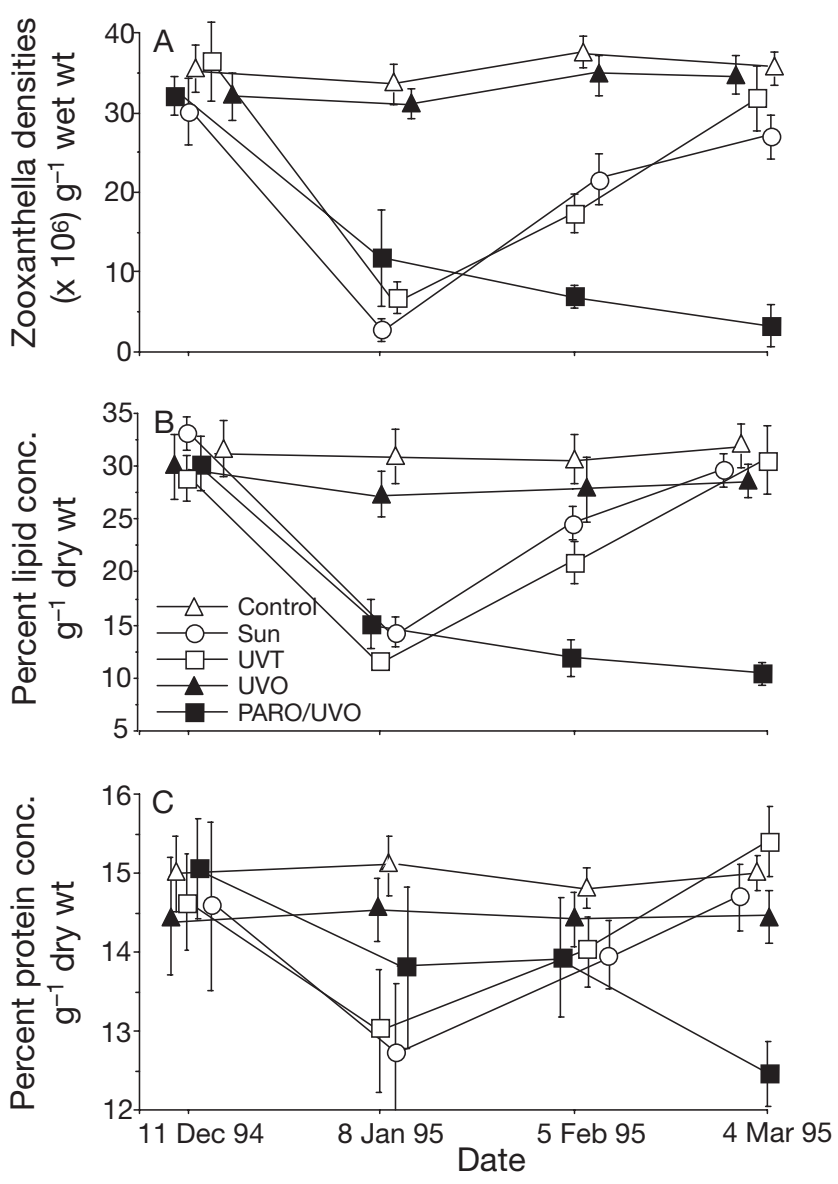

[Nov 94 to Feb 95]). Bite scars on bleached soft corals exceeded those on unbleached soft corals from the same depth by almost $4: 1(19.6 \pm 8.3, \mathrm{n}=37$ and $6.1 \pm$ 2.2 , respectively, $\mathrm{n}=24 ; \mathrm{p}=0.023$ ).

\section{Artificially-bleached soft coral}

Solar radiation can cause bleaching in the soft coral Sinularia maxima (Fig. 3A). The presence of UV-light resulted in significant losses of zooxanthellae, as well as declines in lipid, protein and pukalide concentrations (Fig. 3B-D). When a deep-water population of $S$. maxima was transplanted to shallow water, corals exhibited a reduction (within $1 \mathrm{mo}$ ) in zooxanthellae similar to that of naturally-bleached soft corals (Fig. 3A; open circles). However, at least 2 of our bio-
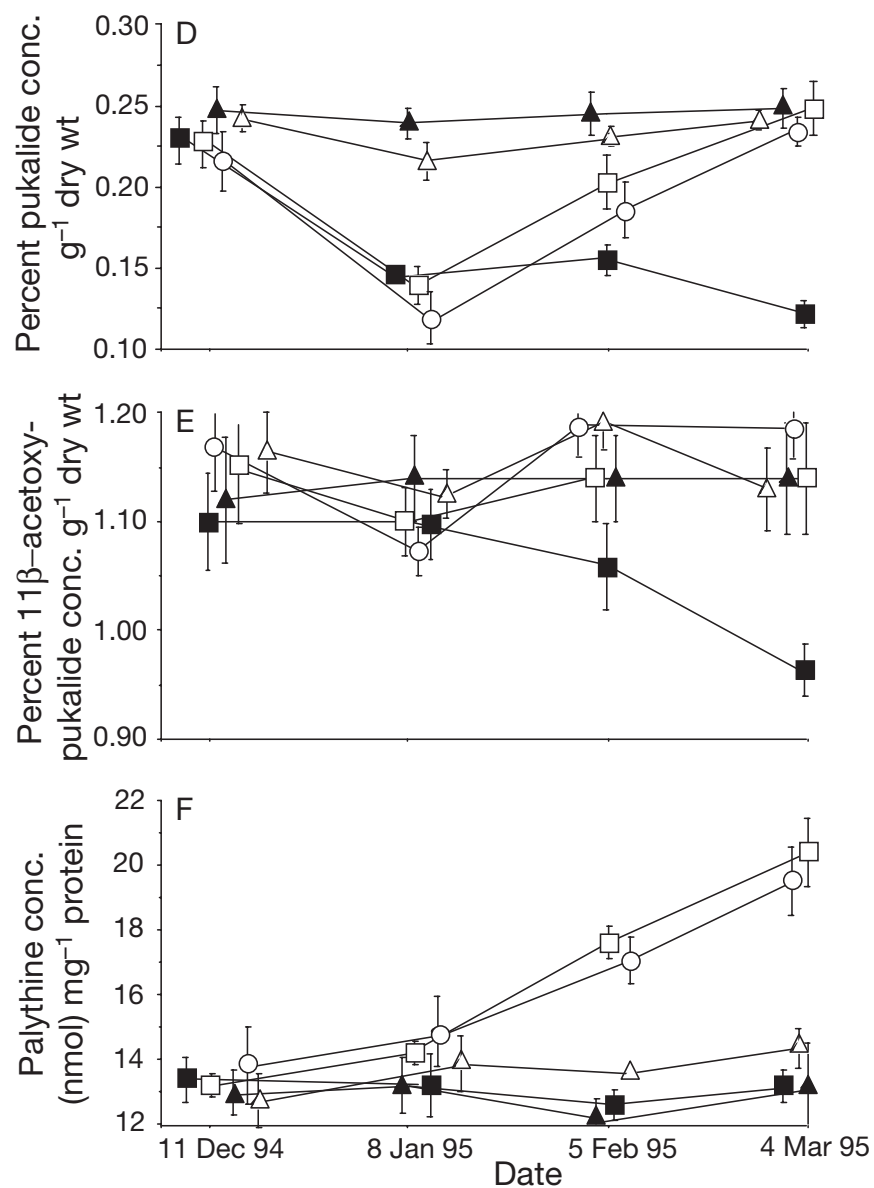

Fig. 3. Changes in zooxanthella densities and biochemical concentrations in the soft coral Sinularia maxima following an artificial bleaching experiment. Compared are soft corals transplanted from $15 \mathrm{~m}$ depth to $1 \mathrm{~m}$ depth into 4 treatments: full sunlight (O), shaded with UV transparent plexiglass (UVT: $\square$ ), shaded with UV opaque plexiglass (UVO: $\mathbf{\Delta}$ ), and shaded with PAR/UV opaque plexiglass (PARO/UVO: $\mathbf{\square})$ each month from November $1994\left(\mathrm{~T}_{0}\right)$ to February $1995\left(\mathrm{~T}_{3}\right)$. Control soft corals $(\Delta)$ were collected at $15 \mathrm{~m}$ and then returned to their site of origin (i.e. back-transplant procedural controls). Data points represent the mean $( \pm \mathrm{SD} ; \mathrm{n}=10$ replicates per treatment) for (A) zooxanthella densities, (B) \% lipid concentration, (C) \% protein concentration, (D) \% pukalide concentration, (E) \% $11 \beta$ acetoxypukalide concentration, and (F) palythine concentration. Note difference in scales (y-axis) for each parameter 
markers (protein and palythine) displayed slightly different responses under artificial bleaching conditions. Specifically, naturally bleached soft corals initially had significantly lower levels of palythine prior to recovery, while artificially bleached colonies appeared to have stable levels of this sunscreen prior to recovery. Protein profiles were similar, although the artificially bleached colonies recovered faster. Back-transplants into the deep reef (15 m, Fig. 3 open triangles) and the shallow reef $(1 \mathrm{~m})$ exhibited no significant handling effects on zooxanthellae or biochemical constituents, however, shallow to deep transplants also bleached and failed to recover, much like the PARO/UVO samples (data not shown). The recovery of soft coral lipid and pukalide to pre-bleaching levels occurred within a 1 to 2 mo period (Scheffe's $S: \mathrm{p}<0.05$ at $\mathrm{T}_{2}$ [8 Jan 95] and $\mathrm{T}_{3}$ [5 Feb 95] for lipid and pukalide concentration), as noted in naturally-bleached soft corals (Fig. 2B,D). The deep to shallow transplants and UVT treatments resulted in a significant induction of palythine over time (Fig. 3F: Scheffe's $S: \mathrm{p}<0.05$ at $\mathrm{T}_{2}$ and $\mathrm{T}_{3}$ ). The reduction of solar radiation (PARO/UVO: see Fig. 1) also resulted in bleaching, albeit more extreme; in addition to the loss of zooxanthellae, lipid, and pukalide (ANOVA $_{\text {zooxanthellae: }} \mathrm{MS}=15.252, F_{3,280}=29.586, \mathrm{p}<$ $0.0001 ;$ ANOVA $_{\text {lipid }}: \mathrm{MS}=706.590, F_{3,280}=19.120, \mathrm{p}<$ $0.0001 ;$ ANOVA $_{\text {pukalide }}: \mathrm{MS}=0.048, F_{3,280}=35.982, \mathrm{p}<$ 0.0001; Scheffe's $S: \mathrm{p}<0.05$ at $\mathrm{T}_{1}$ to $\mathrm{T}_{3}$ [Jan to Mar 95] for zooxanthella densities, lipid and pukalide

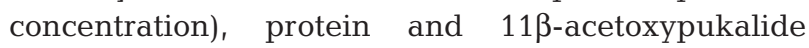
also exhibited significant declines in concentration (ANOVA protein : MS $=8.390, F_{3,280}=3.649, \mathrm{p}=0.0162$; ANOVA $_{11 \beta \text {-acetoxypukalide: }} \mathrm{MS}=0.039, F_{3,280}=3.882, \mathrm{p}=$ 0.0122 ; Scheffe's $\mathrm{S}: \mathrm{p}<0.05$ at $\mathrm{T}_{3}$ for protein and $11 \beta$ acetoxypukalide concentrations, respectively). Moreover, the PARO/UVO shaded soft corals did not recover with time (Fig. 3A).

\section{Feeding deterrence assays}

Crude extracts of the bleached and unbleached soft corals from shallow- and deep-water populations varied in their palatability to the omnivorous pufferfish Canthigaster solandri (Fig. 4A). The extracts from the unbleached soft corals were a deterrent to these predators, while the bleached soft coral extract apparently stimulated feeding (Fig. 4A: significantly more treatment cubes consumed relative to control). Feeding assays with the extracts of light-shaded soft corals provided 3 separate outcomes: (1) UVO-shaded soft corals contained feeding deterrent extracts, (2) UVTshaded soft corals contained feeding stimulant extracts, and (3) PARO/UVO-shaded soft corals contained non-deterrent extracts (Fig. 4B). In $4 \times 3$ blocked

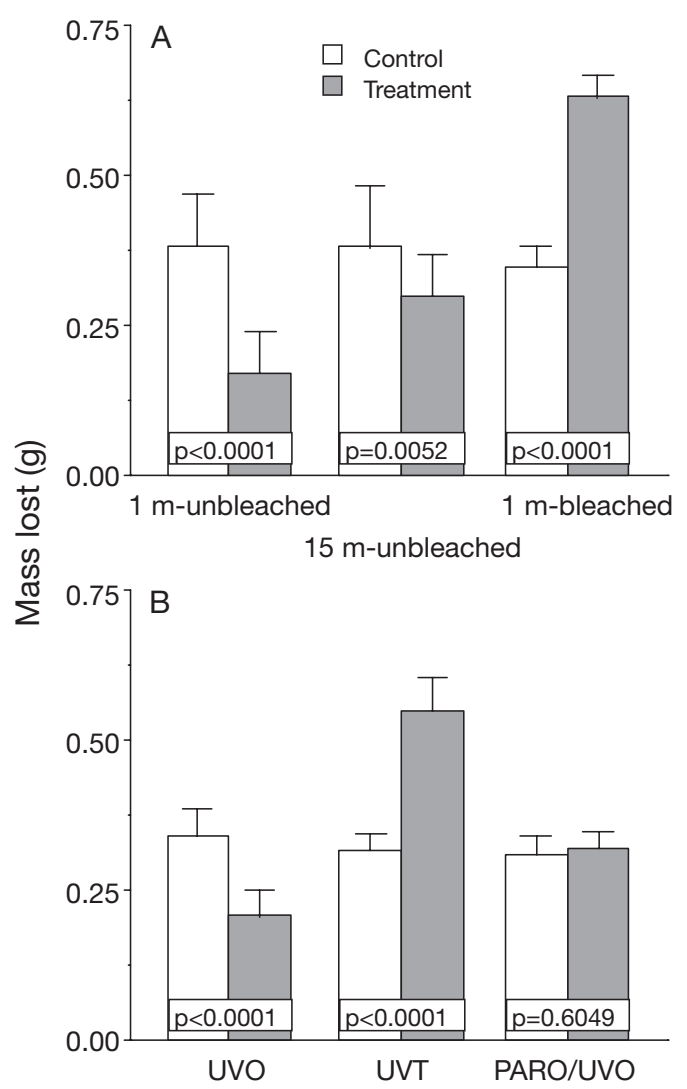

Fig. 4. Feeding effects of Sinularia maxima extracts on the generalist pufferfish Canthigaster solandri in the laboratory. Histograms represent the mean food cube mass lost $(+\mathrm{SD} ; \mathrm{n}=$ 15 replicates per treatment) to feeding pufferfish standardized to food cube hydration via no-fish controls. Compared are: (A) extracts from unbleached soft corals at $1 \mathrm{~m}$ and $15 \mathrm{~m}$ depth, and bleached soft corals at $1 \mathrm{~m}$ depth, and (B) extracts from soft corals treated to 3 different light conditions: UV opaque, UV transparent, and UV/PAR opaque shading

pairwise comparisons of amended diets, pukalide alone was deterrent only at the highest concentration (Fig. 5A,C), while lipid alone appeared to lose nutritional attractiveness at about $10 \%$ (Fig. 5C,D). When the lipid and pukalide content were simultaneously manipulated within the artificial food cubes, fish were more influenced by pukalide concentration than by lipid concentration (Fig. 5A,D: ANOVA High:High: p < 0.0001; ANOVA $_{\text {Low:Low: }} \mathrm{p}=0.0042$ ). A high concentration of pukalide mixed with a low concentration of lipid (i.e. Fig. 5C: P+L) was the least attractive diet option to the fish, but the constitutive effects were additive only (ANOVA: $p=0.0753$ ).

\section{DISCUSSION}

Naturally-induced Sinularia maxima bleaching resulted in significant reductions in lipid, pukalide and 


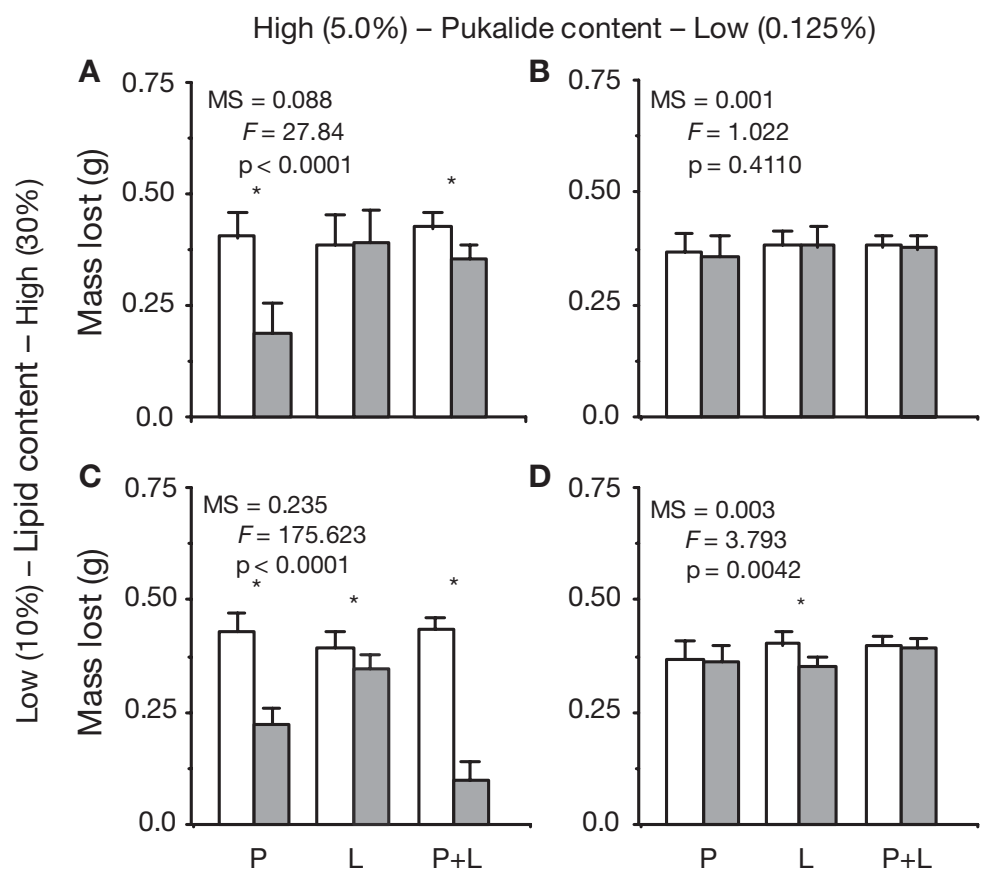

Fig. 5. Feeding effects of the Sinularia maxima defensive compound pukalide, and lipid on the generalist pufferfish Canthigaster solandri in the laboratory. Histograms represent the mean food cube mass lost (+ SD; $\mathrm{n}=15$ replicates per treatment) to feeding pufferfish standardized to food cube hydration via no-fish controls. Open bars designate results from control food cubes, while shaded bars designate results from the treatment food cubes. Compared are assays which combined: (A) high levels of pukalide with high levels of lipid, (B) low levels of pukalide with high levels of lipid, (C) high levels of pukalide with low levels of lipid, and (D) low levels of pukalide with low levels of lipid. All feeding assays were conducted for identical periods of time in order to allow ANOVA comparisons between assays. $\mathrm{P}=$ pukalide, $\mathrm{L}=$ lipid

palythine concentrations, but not protein or 11ß-acetoxypukalide concentrations. However, experimentally-bleached soft corals also exhibited a significant reduction in protein, but no change in palythine concentration. These differences in biomarker response may represent some of the inherent differences between the shallow (naturally-bleached: Nov 94) and deep (experimentally-bleached: Dec 94) populations of $S$. maxima; protein is especially labile over environmental gradients (Slattery \& McClintock 1995). Lipid, an important energy reservoir in cnidarians (Stimson 1987), can be supplied to host tissues by translocation from zooxanthellae symbionts (Falkowski et al. 1984). The loss of zooxanthellae-derived nutrients following symbiont loss (i.e. bleaching) can have a negative impact on coral health and growth (Muller-Parker \& D'Elia 1997, Baker 2001). Significant reduction in $S$. maxima lipid following bleaching implies that zooxanthellae-derived nutrients are an important component of the overall energetic budget of this soft coral and that potential compensatory trade-offs in metabolic activi- ties will be requisite with the loss of this resource. In general, energetic resources should be allocated among growth, reproduction, maintenance, acquisition and defense (Cronin 2001). When resources become limiting, stressed organisms often favor production of defensive metabolites over the other metabolic requirements (Gershenzon 1994). On the other hand, stress can also result in biochemical changes that increase prey attractiveness to predators and/or reduce defenses (EST; White 1984, Rhoades 1985, Cronin \& Hay 1996a). We noted a decrease in levels of the defensive metabolite pukalide during bleaching, as predicted by the EST, but no change in $11 \beta$-acetoxypukalide concentration. Michalek-Wagner \& Bowden (2000) argued that increases in 3 defensive metabolites by 2 species of soft corals in Australia following a bleaching experiment maintained protection against bacterial infections during this period of physiological stress. Their findings were particularly relevant since the antibacterial metabolite flexibilide was produced preferentially over the anti-predator metabolite sinulariolide. Pukalide and 11 $\beta$-acetoxypukalide are both important predator deterrent compounds for Sinularia maxima (Wylie \& Paul 1989, Slattery et al. 2001), and both have modest antimicrobial activity (Slattery et al. 2001), so it is unclear why the latter compound was favored over the former. However, 11ß-acetoxypukalide appears to be far less labile than pukalide (Slattery et al. 2001), and maintenance of either defensive metabolite during a period of environmental stress could be adaptive (Michalek-Wagner \& Bowden 2000) since both compounds share overlapping ecological functions. The reduction of pukalide during bleaching, despite the fact that cembranoid diterpenes are apparently biosynthesized by octocorals (Kokke et al. 1984, Michalek-Wagner et al. 2001), suggests that either translocated energetic resources from symbionts are used to fuel pukalide biosynthesis, or symbiont-derived translocated products act as the biosynthetic precursors to this molecule.

In contrast, mycosporine-like amino acids (including palythine) are sunscreen products of the shikimate biosynthetic pathway that is present in bacteria and primary producers but not in animals (Shick et al. 1999), although there is increasing evidence that metazoan consumers can convert bioaccumulated precursor MAAs into secondary MAA products (Shick 2004). The decline in palythine concentrations in Sinularia max- 
ima following bleaching (Fig. 2F) and subsequent increases in palythine following zooxanthella recovery, supports sunscreen synthesis by the symbionts. Translocation of MAAs to host tissue is a common phenomenon (e.g. Gleason \& Wellington 1995, Adams \& Shick 1996), and some MAAs are maintained or increased by host tissues even when symbiont populations decline (Shick et al. 1999). The relatively rapid change in palythine concentration (in direct correlation with zooxanthellae abundance) implies the sunscreen is largely sequestered within symbiont rather than host cells in S. maxima. Significantly, our data indicate that palythine production may be an inducible response to increases in UVR (Fig. 3F), presumably to limit photo-damage (Gleason \& Wellington 1995, Adams \& Shick 1996). Inducible chemical defenses have been well documented in terrestrial plant-herbivore associations (Karban \& Baldwin 1997), and rarely in marine algae-grazer interactions (Cronin \& Hay 1996b, Toth et al. 2007). However, inducible chemical defenses may be a relatively important mechanism of coping with light stress (e.g. Zangerl \& Berenbaum 1987, Torregiani \& Lesser 2007). Prior work with zooxanthellae-host associations also indicated that light acclimatization is due to genetic variability of the symbionts (Rowan et al. 1997), although the phenotypic characteristics that are responsible for increased resistance to light quality and/or quantity were not elucidated.

Recovery of the soft corals following bleaching was a relatively rapid event; within 2 mo of a natural or experimentally-induced bleaching event, symbiont populations had returned to pre-bleached levels in Sinularia maxima. Likewise, soft corals transplanted from depth to the shallow reef flat lost about $85 \%$ of their symbiont populations in a month, and within another month, zooxanthellae concentration had recovered to about $80 \%$ of the original levels. These recovery rates are about 3 to 4 mo faster than those observed by Michalek-Wagner \& Willis (2001) in the soft coral Lobophytum compactum. Some of these differences might be due to species-specific and/or symbiont clade differences (Hofmann 1999, Rowan et al. 1997, respectively). Alternatively, degree of stress appears to be an important consideration in the severity of bleaching and the rate of recovery. We subjected S. maxima to differential light stress only, while Michalek-Wagner \& Willis (2001) induced bleaching via a combination of light and temperature extremes. In studies with Lobophytum compactum and Sinularia flexibilis, artificial bleaching procedures resulted in biochemical responses different from those in the same species collected in the field during the 1998 GBR (Great Barrier Reef, Australia) bleaching event. Michalek-Wagner \& Bowden (2000) observed signifi- cant increases in defensive metabolite levels (sinulariolide, isolobophytolide, and flexibilide) during the natural bleaching event, but noted decreased levels of these metabolites when soft corals were experimentally bleached. These researchers concluded that duration of stress and possibly the added stress of freshwater run-off in the field were responsible for these differences between natural and experimentallyinduced bleaching. Evidence has accumulated to suggest that bleaching is not the harbinger of coral reef death (Muller-Parker \& D'Elia 1997, Rowan et al. 1997), and bleaching may represent a mechanism to ensure that hosts periodically turn over their symbiont populations in favor of better stress-adapted individuals that can tolerate environmental changes (Baker 2001, but see Hoegh-Guldberg et al. 2002). Our study assessed the 'holobiont' so it is unclear whether recovery represents an infection by new symbionts or survival and replication of some of the original symbiont population (Barneah et al. 2004). Bleaching due to increased UV radiation has been previously documented (e.g. Gleason \& Wellington 1993), but the importance of incident light quality to zooxanthellae stability within cnidarian hosts has rarely been discussed. For example, the near absence of all solar irradiance (PARO/UVO shades: Fig. 3) resulted in zooxanthellae loss in Sinularia maxima within 1 mo. As noted, under natural bleaching conditions these soft corals exhibited significant reductions in pukalide and palythine concentrations. However, soft corals shaded in this manner did not recover symbionts, and this ultimately took its toll on other biochemical constituents (i.e. declines in protein and $11 \beta$-acetoxypukalide), further demonstrating the importance of the host-symbiont association (Muller-Parker \& D'Elia 1997). Our results imply that $S$. maxima cannot sustain populations of zooxanthellae symbionts without light, and that extended symbiont-free periods are detrimental to the health of this soft coral (Baker 2001, McClanahan 2004) and, possibly, the coral reef community (McClanahan et al. 2001).

Sinularia maxima feeding deterrence was significantly impacted by bleaching, either natural or experimentally-induced. Naturally-bleached soft corals were more susceptible to predation than unbleached soft corals by about 4:1 (based on our field observations of bite scars produced by a suite of coral reef fishes, e.g. butterflyfishes, angelfishes, and pufferfishes: M. Slattery pers. obs.). Extracts of bleached individuals actually stimulated feeding by an omnivorous pufferfish Canthigaster solandri (Fig. 4A). These results support the EST hypothesis in that stressed soft corals became more attractive to predators than unstressed (i.e. unbleached) individuals. Renaud et al. (1990) and Cronin \& Hay (1996a) were the only previous marine 
studies to assess the effect of abiotic stressors on prey chemical defenses. They examined differences in palatability of the temperate alga Dictyota menstrualis subjected to variable dessication regimes and noted higher levels of grazer preference for the more severely stressed thalli. Additional studies have demonstrated reduced food preference due to biochemical factors other than chemical defenses (e.g. Goranson et al. 2004). Our work provided somewhat puzzling results on the biochemical stress-related changes that lead to increased soft coral palatability. We expected, a priori, to see reductions in all of the defensive metabolites to account for the observed increased levels of predation on naturally-bleached individuals. Our expectations were based on prior work that indicated minimal concentrations of pukalide and $11 \beta$-acetoxypukalide $(0.5 \%$ and $1.1 \%$, respectively) deter predation by Canthigaster solandri (Slattery et al. 1998, 2001), and that lipid levels often dictate feeding behavior (Stimson 1987). However, while pukalide levels decreased there was no significant change in $11 \beta$-acetoxypukalide levels following bleaching. Thus to counteract the feeding deterrent effects of $11 \beta$-acetoxypukalide, lipid and pukalide levels would have to rise and fall, respectively. That lipid levels also dropped, despite an increase in prey palatability, suggests that specific constituents of the lipid were disproportionately lost resulting in an increased percentage in specific feeding attractant constituents (Bachok et al. 2006). For example, lipid constituents typically include polyunsaturated fatty acids; these would be susceptible to degradation by light or radical oxidation (an indirect effect of UVR) and would therefore change the ratio of this biochemical component and might account for changes in attractiveness. Moreover, these results support previous data that indicate $11 \beta$-acetoxypukalide is not as bioactive as pukalide (Slattery et al. 2001), and seem to indicate that other nutritional qualities of the crude extract (e.g. insoluble proteins, carbohydrates etc) mask the deterrent effects of this compound (Simpson \& Raubenheimer 2001). It is clear that further work is required in order to ascertain the specific mechanisms by which bleaching impacts feeding susceptibility in Sinularia maxima, and the role of the zooxanthellae symbionts will need to be considered (e.g. Michalek-Wagner et al. 2001). However, our results support the EST model and indicate that the indirect consequences of bleaching might have a greater impact on the health of the soft coral (e.g. tissue damage due to predation) than the temporary loss of symbionts. As consequences of global climate change become more pronounced in shallow tropical marine ecosystems, it is likely that indirect effects of these abiotic stressors will have significant impacts on community dynamics.
Acknowledgements. We thank C. Avila, D. Ginsburg, D. Nagle, B. Novack, M. Puglisi, P. Schupp, J. Starmer, and R. Thacker for their tireless efforts in the field. Y. Benayahu provided taxonomic verification of the species examined in this study; for his help and insights we are extremely grateful. M. Lesser provided MAA standards for analytical analyses, for which we are indebted. Assistance with extractions and analytical chemistry were provided by B. Avery, D. Comfort Jr., B. Laird, W. Walker, M. Warren, and K. Wesson. M. Lesser, D. Gochfeld and D. Nagle provided comments that improved this manuscript. This research was supported by grants from the National Science Foundation OCE 9321533 \& OCE 9528570, MS-AL Sea Grant R/AT-3-PD, and NOAA NA16RU1496 to MS, and the National Institutes of Health GM 38624 to VJP. This is contribution number 615 from the University of Guam Marine Laboratory and contribution number 720 from the Smithsonian Marine Station at Fort Pierce.

\section{LITERATURE CITED}

Adams NL, Shick JM (1996) Mycosporine-like amino acids provide protection against ultraviolet radiation in eggs of the green sea urchin Strongylocentrotus droebachiensis. J Photochem Photobiol 64:149-158

Anthony KRN, Connolly SR, Willis BL (2002) Comparative analysis of energy allocation to tissue and skeletal growth in corals. Limnol Oceanogr 47:1417-1429

Bachok Z, Mfilinge P, Tsuchiya M (2006) Characterization of fatty acid composition in healthy and bleached corals from Okinawa, Japan. Coral Reefs 25:545-554

Baker AC (2001) Reef corals bleach to survive change. Nature 411:765-766

Barneah O, Weis VM, Perez S, Benayahu Y (2004) Diversity of dinoflagellate symbionts in Red Sea soft corals: mode of symbiont acquisition matters. Mar Ecol Prog Ser 275: 89-95

Baruch R, Avishai N, Rabinowitz C (2005) UV incites diverse levels of DNA breaks in different cellular compartments of a branching coral species. J Exp Biol 208:843-848

Brown BE (1997) Coral bleaching: causes and consequences. Coral Reefs 16:S129-138

Cronin G (2001) Resource allocation in seaweeds and marine invertebrates: chemical defense patterns in relation to defense theories. In: McClintock JB, Baker BJ (eds) Marine chemical ecology. CRC Press, Boca Raton, FL, p 325-354

Cronin G, Hay ME (1996a) Seaweed-herbivore interactions depend on the recent history of both the plant and the animal. Ecology 77:1531-1543

Cronin G, Hay ME (1996b) Induction of seaweed chemical defenses by amphipod grazing. Ecology 77:2287-2301

Cruz-Rivera E, Hay ME (2003) Prey nutritional quality interacts with chemical defenses to affect consumer feeding and fitness. Ecol Monogr 73:483-506

Douglas AE (2003) Coral bleaching - how and why? Mar Poll Bull 46:385-392

Duffy JE, Paul VJ (1992) Prey nutritional quality and the effectiveness of chemical defenses against tropical reef fishes. Oecologia 90:333-339

Falkowski PG, Dubinsky Z, Muscatine L, Porter JW (1984) Light and bioenergetics of a symbiotic coral. Bioscience 34:705-709

Gershenzon J (1994) The cost of plant chemical defense against herbivory: a biochemical perspective. In: Bernays EA (ed) Insect-plant interactions. CRC Press, Boca Raton, FL, p 105-173 
Gleason DF, Wellington GM (1993) Ultraviolet radiation and coral bleaching. Nature 365:836-838

Gleason DF, Wellington GM (1995) Variation in UVB sensitivity of planula larvae of the coral Agaricia agaricites along a depth gradient. Mar Biol 123:693-703

Glynn PW (1993) Coral reef bleaching: ecological perspectives. Coral Reefs 12:1-17

Goranson CE, Ho CK, Pennings SC (2004) Environmental gradients and herbivore feeding preferences in coastal salt marshes. Oecologia 140:591-600

Grottoli AG, Rodrigues LJ, Juarez C (2004) Lipids and stable carbon isotopes in two species of Hawaiian corals, Porites compressa and Montipora verrucosa, following a bleaching event. Mar Biol 145:621-631

Hay ME, Kappel QE, Fenical W (1994) Synergisms in plant defenses against herbivores: interactions of chemistry, calcification, and plant quality. Ecology 75:1714-1726

Hoegh-Guldberg O, Jones RJ, Ward S, Loh WK (2002) Is coral bleaching really adaptive? Nature 415:601-602

Hofmann GE (1999) Ecologically relevant variation in induction and function of heat shock proteins in marine organisms. Am Zool 39:889-900

Karban R, Baldwin IT (1997) Induced responses to herbivory. University of Chicago Press, Chicago IL

Karentz D, McEuen FS, Land KM, Dunlap WC (1991) Survey of mycosporine-like amino acid compounds in Antarctic marine organisms: potential protection from ultraviolet exposure. Mar Biol 108:157-166

Kokke WCMC, Epstein S, Look SA, Rau GH, Fenical W, Djerassi C (1984) On the origin of terpenes in symbiotic associations between marine invertebrates and algae (zooxanthellae). J Biol Chem 259:8168-8173

Lesser MP (1997) Oxidative stress causes coral bleaching during exposure to elevated temperatures. Coral Reefs 16: 187-192

McClanahan TR (2004) The relationship between bleaching and mortality of common corals. Mar Biol 144:1239-1245

McClanahan T, Muthiga N, Mangi S (2001) Coral and algae changes after the 1998 coral bleaching: interaction with reef management and herbivores on Kenyan reefs. Coral Reefs 19:380-391

Michalek-Wagner K, Bowden BF (2000) Effects of bleaching on secondary metabolite chemistry of alcyonacean soft corals. J Chem Ecol 26:1543-1562

Michalek-Wagner K, Willis BL (2001) Impacts of bleaching on the soft coral Lobophytum compactum. II. Biochemical changes in adults and their larvae. Coral Reefs 19:240-246

Michalek-Wagner K, Bourne DJ, Bowden BF (2001) The effects of different strains of zooxanthellae on the secondary-metabolite chemistry and development of the soft coral host Lobophytum compactum. Mar Biol 138:753-760

Muller-Parker G, D'Elia CF (1997) Interactions between corals and their symbiotic algae. In: Birkeland C (ed) Life and death of coral reefs. Chapman \& Hall, New York, p 96-113

Renaud PE, Hay ME, Schmitt TM (1990) Interactions of plant stress and herbivory: intraspecific variation in the susceptibility of a palatable versus an unpalatable seaweed to

Editorial responsibility: Joseph Pawlik,

Wilmington, North Carolina, USA sea urchin grazing. Oecologia 82:217-226

Rhoades DF (1985) Offensive-defensive interactions between herbivores and plants: their relevance to herbivore population dynamics and ecological theory. Am Nat 125: 205-238

Rowan R, Knowlton N, Baker A, Jara J (1997) Landscape ecology of algal symbionts creates variation in episodes of coral bleaching. Nature 388:265-269

Shick JM (2004) The continuity and intensity of ultraviolet irradiation affect the kinetics of biosynthesis, accumulation, and conversion of mycosporine-like amino acids (MAAs) in the coral Stylophora pistillata. Limnol Oceanogr 49:442-458

Shick JM, Romaine-Lioud S, Ferrier-Pages C, Gattuso JP (1999) Ultraviolet-B radiation stimulates shikimate pathway-dependent accumulation of mycosporine-like amino acids in the coral Stylophora pistillata despite decreases in its population of symbiotic dinoflagellates. Limnol Oceanogr 44:1667-1682

Simpson SJ, Raubenheimer D (2001) The geometric analysis of nutrient-allelochemical interactions: a case study using locusts. Ecology 82:422-439

Slattery M, McClintock JB (1995) Population structure and feeding deterrence in three Antarctic soft corals. Mar Biol 122:461-470

Slattery M, Avila C, Starmer J, Paul VJ (1998) A sequestered soft coral diterpene in the aeolid nudibranch Phyllodesmium guamensis. J Exp Mar Biol Ecol 226:33-49

Slattery M, Starmer J, Paul VJ (2001) Temporal and spatial plasticity in chemical constituents of tropical Pacific soft corals Sinularia maxima and S. polydactyla. Mar Biol 138: 1183-1193

Spencer Davies P (1991) Effects of daylight variations on the energy budgets of shallow-water corals. Mar Biol 108:137-144

Stimson J (1987) The location, quantity and rate of change in quantity of lipids in tissues of Hawaiian hermatypic corals. Bull Mar Sci 41:889-904

Torregiani JH, Lesser MP (2007) The effects of short-term exposures to ultraviolet radiation in the Hawaiian coral Montipora verrucosa. J Exp Mar Biol Ecol 340:194-203

Toth GB, Karlsson M, Pavia H (2007) Mesoherbivores reduce net growth and induce chemical resistance in natural seaweed populations. Oecologia 152:245-255

Warner ME, Chilcoat GC, McFarland FK, Fitt WK (2002) Seasonal fluctuations in the photosynthetic capacity of photosystem II in symbiotic dinoflagellates in the Caribbean reef-building coral Montastrea. Mar Biol 141:31-38

White TCR (1984) The abundance of invertebrate herbivores in relation to the availability of nitrogen in stressed food plants. Oecologia 63:90-105

Wylie CR, Paul VJ (1989) Chemical defenses in three species of Sinularia (Coelenterata, Alcyonacea)-effects against generalist predators and the butterflyfish Chaetodon unimaculatus Bloch. J Exp Mar Biol Ecol 129:141-160

Zangerl AR, Berenbaum MR (1987) Furanocoumarins in wild parsnip: effects of photosynthetically active radiation, ultraviolet light, and nutrients. Ecology 68:516-520

Submitted: March 22, 2007; Accepted: August 7, 2007

Proofs received from author(s): January 26, 2008 